\title{
AS RESPOSTAS DA CÂMARA DOS DEPUTADOS AO AGRAVAMENTO DA VIOLÊNCIA DOMÉSTICA EM TEMPOS DE PANDEMIA
}

\author{
Strauss Vidrich de Souza ${ }^{1}$ \\ Bruna Helena Aro Misailidis ${ }^{2}$
}

\section{RESUMO}

O presente artigo analisa o problema da violência doméstica contra a mulher sob a situação de isolamento social decorrente da pandemia da Covid-19 para, em seguida, através da análise das proposituras legislativas da Câmara dos Deputados no período em apreço, tecer considerações sobre as iniciativas adotadas como resposta ao problema. O método utilizado foi o dedutivo, de modo que se objetivou fazer avaliação exaustiva a fim de identificar se a reação legislativa em situação de risco acompanhou as diretrizes da Lei Maria da Penha enquanto política de Estado, o que se concluiu ser o caso.

Palavras-chave: Violência doméstica; Pandemia; Proposituras legislativas; Lei Maria da Penha; Criminologia.

\section{THE RESPONSES OF THE CHAMBER OF DEPUTIES TO THE WORSENING OF DOMESTIC VIOLENCE IN PANDEMIC TIMES}

\begin{abstract}
This article analyzes the problem of domestic violence against women under the situation of social isolation resulting from the Covid-19 pandemic, and then, through the analysis of the legislative proposals of the Chamber of Deputies in the period under review, to make considerations about the initiatives adopted in response to the problem. The deductive method was used, so that the objective was to carry out an exhaustive assessment in order to identify whether a legislative reaction at risk accompanied the guidelines of the Maria da Penha Law as a State policy, which was concluded to be the case.
\end{abstract}

Keywords: Domestic violence; Pandemic; Legislative proposals; Maria da Penha Law; Criminology.

\section{INTRODUÇÃO}

A presente pesquisa se debruça sobre as proposituras legislativas apresentadas na Câmara dos Deputados, exclusivamente como resposta ao aumento das notificações de violência doméstica contra a mulher durante o primeiro ano da pandemia de Covid-19.

\footnotetext{
${ }^{1}$ Mestrando em Direito pela Pontifícia Universidade Católica de Campinas (PUC-Campinas). Especialista em Direito Penal e Criminologia pelo Instituto de Criminologia e Política Criminal (ICPC/Uninter). Bacharel em Direito pela Pontifícia Universidade Católica de Campinas (PUC-Campinas).

${ }^{2}$ Mestranda em Direito pela Pontifícia Universidade Católica de Campinas (PUC-Campinas). Graduada em Direito pela Pontifícia Universidade Católica de Campinas (PUC-Campinas).
} 
A situação de risco trazida pelo contágio do coronavírus trouxe contrastes na forma de se relacionar, com inclinações ao isolamento social, o que foi um fator determinante para o agravamento da violência doméstica contra a mulher. Em que pese seus números exatos não possam ser adequadamente mensurados, é de se notar que a quantidade de relatos acerca do tema, bem como a frequência com que o poder judiciário foi chamado a intervir, tiveram alterações expressivas no período em apreço.

Deste modo, em um primeiro momento, o artigo contextualizará o reconhecimento no âmbito do direito internacional das relações de desigualdade e violência contra a mulher a partir de uma perspectiva de opressão baseada no gênero.

Em seguida, após análise de diretrizes da Lei Maria da Penha e sua relação com a situação de risco decorrente da pandemia de Covid-19, serão levantados dados que evidenciam como, quando e a que nível as situações de violência doméstica se deram no contexto de isolamento social.

Por fim, serão enumerados os tipos de proposições legislativas, suas justificativas, representatividade, período de apresentação, inspiração, transitoriedade e, por fim, o destino que tiveram. A pesquisa buscará, nesse sentido, tecer considerações norteadas pelos princípios adotadas pela Lei Maria da Penha e conceitos desenvolvidos pela criminologia crítica para identificar se houve planejamento e coerência nos projetos de lei apresentados.

É esperado que as conclusões acerca do comportamento da Câmara dos Deputados em período tão conturbado e sobre tema demasiado delicado possam contribuir para a elucidação de como pensam os parlamentares quando se aborda o tema da violência doméstica e orientar a política criminal elaborada sobre esse problema.

\section{VISIBILIDADE INTERNACIONAL SOBRE A VIOLÊNCIA BASEADA NO GÊNERO}

A desigualdade entre homens e mulheres é questão reconhecida nos tratados internacionais de Direitos Humanos, todos incorporados pelo Brasil, na esfera infraconstitucional. Os primeiros passos dados em direção a uma superação dessa assimetria 
surgem com o tratamento igualitário dispensado a homens e mulheres na Carta das Nações Unidas $(1945)^{3}$.

A Convenção sobre a Eliminação de Todas as Formas de Discriminação contra a Mulher (1979), primeiro tratado a abordar o tema de maneira específica, oferece a definição jurídica da discriminação enquanto violência baseada no sexo ${ }^{4}$. É somente com a Convenção Interamericana para Prevenir, Punir e Erradicar a Violência contra a Mulher (1994) Convenção de Belém do Pará -, aprovada a nível regional-especial, que o gênero passa a ser utilizado como parâmetro de compreensão da violência ${ }^{5}$.

A adoção do conceito de gênero ao invés do conceito de sexo para designar a relação de violência decorre de adequação terminológica, que passa a identificar as camadas de opressão inerentes à sociedade patriarcal.

Para Butler (2018), gênero nada mais é do que uma construção social, algo que não parte da natureza biológica do ser humano, mas cujo significado é socialmente determinado e que dele é esperado enquanto comportamento de acordo com seu sexo. O sexo, por sua vez, são características biológicas e congênitas que diferenciam homens e mulheres. São, portanto, dois termos que devem ser considerados separadamente.

No mais, a autora também indica que essa determinação permanece flutuante, de modo que o ato de se tornar mulher não deve se restringir somente a um determinado sexo biológico, mas à formação de sua individualidade.

Quebrando, assim, a dualidade existente entre sexo e gênero, a relação de violência sobre a mulher deve ser observada a partir daquilo que significa ser mulher dentro das estruturas sociais postas ${ }^{6}$.

\footnotetext{
${ }^{3}$ Como observa Willeman (2000), em que pese o conteúdo da Carta assinada pelos países, nesse ponto apenas 35 dos 51 signatários reconheciam à mulher, em seu ordenamento jurídico interno, o direto ao sufrágio ou o de exercer função pública.

${ }^{4}$ Segunda consta: "Artigo $1^{\circ}$ - Para os fins da presente Convenção, a expressão "discriminação contra a mulher" significará toda a distinção, exclusão ou restrição baseada no sexo e que tenha por objeto ou resultado prejudicar ou anular o reconhecimento, gozo ou exercício pela mulher, independentemente de seu estado civil, com base na igualdade do homem e da mulher, dos direitos humanos e liberdades fundamentais nos campos político, econômico, social, cultural e civil ou em qualquer outro campo."

${ }^{5}$ Nesse sentido: "Artigo 1 - Para os efeitos desta Convenção, entender-se-á por violência contra a mulher qualquer ato ou conduta baseada no gênero, que cause morte, dano ou sofrimento físico, sexual ou psicológico à mulher, tanto na esfera pública como na esfera privada." O conceito de gênero foi enfim definido na agenda internacional quando da realização da IV Conferência Mundial sobre a Mulher, pela Organização das Nações Unidas.

${ }^{6}$ Acompanhamos o entendimento de Butler (2018), segundo o qual a construção do termo "mulher" não encerra o conteúdo biológico. Desse modo, conforme observa Massaro (2021), a violência contra a mulher abrange todas aquelas que se identificam com o gênero mulher, independentemente de seu sexo biológico.
} 
Logo, é possível extrair a seguinte conclusão: a mulher, nascida com as respectivas características biológicas de mulher ou adquirida a identidade enquanto formação do ser em sociedade, tem sobre si a expectativa social de viver e de se comportar de determinado modo, geralmente restrita ao ambiente privado (doméstico). Sobre si, são esperados os papéis sociais da mulher "dona do lar", "frágil", "submissa" e "dependente". Por outro lado, quando não preenche tais expectativas, tende a sofrer represálias sociais, pois estaria em desacordo com uma cultura posta e, de certa forma, imposta à sua condição de ser mulher ${ }^{7}$.

É interessante notar que as relações de opressão em muito dizem respeito à exploração da mulher como objeto de posse na sociedade patriarcal. Enquanto luta para se impor na sociedade, a mulher enfrenta resistência vinda dos convívios inerentes às relações de trabalho e à propriedade privada. No ambiente doméstico, a mulher, que antes costumava pertencer a seu pai, com o advento do matrimônio é entregue ao marido, sem que possa em algum momento ser percebida como dona de si mesma ${ }^{8}$.

Hodiernamente, a percepção de posse e desvalorização da mulher possui suas raízes plantadas nas relações domésticas, o que faz com que homens entendam ser donos de suas esposas, companheiras, namoradas, mães, filhas, e a lista se estende, como se fossem capazes de mandar em seus corpos, em seus trabalhos, em suas vidas ${ }^{9}$.

Com base em todo o exposto, é possível perceber que a constante luta das mulheres ainda possui muitos entraves e, apesar de um reconhecimento de igualdade formalmente estabelecido, as desigualdades materiais ainda permanecem.

Nesse sentido, a compreensão das relações inerentes à sociedade patriarcal leva à conclusão de que ela se caracteriza por reservar à mulher posição restritiva de sua liberdade e plena autonomia, de modo que a desigualdade de gênero que favorece a preponderância do patriarcado sobre o corpo da mulher deve ser entendida como fio condutor da violência doméstica.

\footnotetext{
${ }^{7}$ Esse fenômeno pode ser compreendido a partir do conceito de "violência simbólica" desenvolvido por Bourdieu (2012). Segundo o autor, modos de convívio e categorias instituídas pelos sujeitos dominantes são aplicadas sobre os sujeitos dominados e por eles (elas) absorvidas enquanto forma natural de participação em sociedade. Assim, a dominação simbólica se faz presente sem que, para tanto, seja preciso aplicar a coação física. O autor também destaca a associação do ambiente público (a praça) reservado ao masculino, ao passo que o ambiente privado (a casa) permanece destinado ao feminino.

${ }^{8}$ Conforme digressão feita por Beauvoir (2009). Bourdieu (2012) ainda indica que a dominação masculina impõe à mulher a noção de que somente ganha valor quando vem a pertencer através do matrimônio.

${ }_{9}^{9}$ Ao que expõe Saffíoti (2004), a violência contra a mulher é muito mais recorrente em situação intrafamiliar (privada) do que na esfera pública.
} 


\section{O AGRAVAMENTO DA VIOLÊNCIA DOMÉSTICA EM RAZÃO DA PANDEMIA} DA COVID-19

Dentro da lógica das questões de gênero tratadas anteriormente, bem como inspirada no avanço da legislação internacional de Direitos Humanos, se edificou a Lei Maria da Penha - Lei n. ${ }^{\circ}$ 11.340/06. Sua promulgação representou grande avanço das lutas feministas e passou a orientar estrategicamente o enfrentamento da violência doméstica em âmbito nacional, em especial objetivando a retomada da autonomia da mulher em situação de violência ${ }^{10}$.

Não obstante, o paradigma da opressão observada pela criminologia feminista, oposta também como convite à reanálise da criminologia crítica, demonstra a potencial inserção da situação de violência sobre a mulher não só no espaço público, mas também no privado $^{11}$. Essa dinâmica é determinante para a caracterização da cifra oculta desse tipo de delito, posto que produz obstáculos adicionais ao alcance do amparo estatal ${ }^{12}$.

É preciso notar que a mulher em situação de violência é prisioneira do espaço doméstico. Diversos fatores, tais como o desprestígio familiar e social decorrentes de uma separação, a sensação de debilidade, a dependência econômica, a insegurança no cuidado dos filhos, entre outros, além de serem consequências construídas a partir ou por meio da estrutura patriarcal, também criam barreiras que incentivam a permanência da mulher no convívio de violência ${ }^{13}$.

Por esse motivo, é intuitivo supor que o isolamento social, imposto como prática necessária à contenção da pandemia da Covid-19, teria como consequência o agravamento do problema da violência doméstica contra a mulher, na medida em que obriga a constante

\footnotetext{
${ }^{10}$ Essa é a observação de Campos e Carvalho (2011). Complementam que o próprio estigma decorrente da designação de "vítima" é objeto de crítica pela corrente feminista abraçada pela Lei Maria da Penha, tendo em vista que essa definição coloca a mulher enquanto objeto passivo da violência. No lugar, o uso da expressão "mulher em situação de violência" parece mais adequado, vez que indica o resgate da condição de sujeito e do caráter transitório de sua condição.

${ }^{11}$ Enquanto a criminologia crítica representou verdadeira mudança de paradigma na medida em que retira o foco de análise do criminoso para direcioná-lo aos processos de criminalização, como expõe Baratta (2011), a criminologia feminista denunciou outros níveis da violência produzida sobre a mulher em decorrência da aplicação da lei penal, como nos momentos que a invisibiliza, revitimiza ou institui duplo grau de punição, conforme apresentado por Mendes (2014).

${ }^{12}$ Estima-se que somente $40 \%$ dos crimes de violência contra a mulher sejam reportados, o que representa um dos ilícitos com mais altas taxas de cifra oculta. Nesse sentido, United Nations $(2015$, p. 159).

${ }^{13}$ A respeito do impacto da violência sobre a mulher, ver Netto et al. (2014).
} 
coexistência com o agressor, a afasta de redes de apoio, gera tensões de risco social e acarreta crises econômicas $^{14}$.

A relevância da questão advém de que, por anos, a luta feminista se voltou a dar visibilidade à violência praticada contra a mulher, especialmente no âmbito doméstico, circunstância que volta a ser invisibilizada em decorrência do isolamento social. A evidência da maximização do fenômeno se dá com o trabalho de observatórios de mídia e relatórios constituídos por dados oficiais.

Assim, com a finalidade de se aprofundar mais na realidade atual dos casos de violência doméstica, o presente estudo teve como base o Anuário Brasileiro de Segurança Pública (2020), produzido com respaldo nas informações trazidas pelas secretarias de segurança pública estaduais, pelo Tesouro Nacional, pelas polícias civis, militares e federal, dentre outras fontes oficiais da Segurança Pública, a partir do qual foram extraídas as conclusões expostas a seguir.

Primeiramente, enquanto houve uma notável redução no número de denúncias por violência doméstica, após o advento do isolamento social, paradoxalmente houve um considerável aumento na quantidade de ligações recebidas pelo plantão 190, registradas sob a natureza de violência doméstica. Assim, temos que, ao passo que diminuíram os registros de ocorrências de crimes como lesão corporal dolosa (-9,6\%), ameaça (-16,7\%), estupro ($22,4 \%)$ e estupro de vulnerável $(-22,1 \%)$, entre os meses de março, abril e maio de 2020 , é de se notar que os crimes de violência letal contra a mulher cresceram $(+2 \%$ para homicídios dolosos contra a mulher; $+2 \%$ para feminicídio), bem como as ligações ao plantão 190 $(+3,8 \%)$.

A queda no registro de ocorrência desses crimes tem forte relação com a necessidade de a mulher em situação de violência comparecer fisicamente à delegacia, o que demanda o seu deslocamento em um momento em que vigem restrições de acesso ao espaço público e, também, a necessidade de maior permanência no convívio doméstico, com o agressor. $\mathrm{O}$ resultado é o silêncio, que concorre para o aumento dos casos de violência doméstica, cumulado com o aumento das dificuldades enfrentadas para realizar a denúncia; inclusive, no mesmo período os serviços de proteção à mulher quedaram-se instáveis, em virtude das medidas de restrição e isolamento adotadas na pandemia.

\footnotetext{
${ }^{14}$ Nesse sentido, existem indicativos de que lares em que o parceiro acatou as orientações de isolamento social refletiram um aumento nos índices de violência doméstica, conforme Perez-Vincent et al. (2020).
} 
Ainda, com a diminuição das denúncias, consequentemente, diminuiu a quantidade de medidas protetivas de urgência concedidas às mulheres em situação de violência, que poderiam evitar um agravamento dos casos, a sua repetição, ou, no limite, o feminicídio ${ }^{15}$.

Dessa forma, desamparada em momentos de dificuldade, a mulher em situação de violência se vê inibida de agir, e não apenas por conta do medo que advém do convívio conjunto com o agressor, mas também, é de se destacar, pela falta de certeza de que será alcançada pelas medidas de amparo adotadas pelo poder público. Além disso, por mais que o Brasil já tenha se posicionado e adotado certas medidas, como a criação de aplicativos online e ampliação dos canais telefônicos para realização de denúncias, estas têm se mostrado insuficientes.

Nesse mesmo sentido foram os estudos realizados pelo Instituto Igarapé, quando lançou a primeira atualização de dados da plataforma Evidências sobre Violências e Alternativas para Mulheres e Meninas (EVA), "ferramenta que mapeia uma série de medidas de violência contra mulheres e meninas no Brasil, Colômbia e México" (GIANNINI et al., 2020). Suas pesquisas indicaram três sérios problemas ao longo de 2020: a) altos índices de violência contra a mulher; b) baixos índices de denúncias; e c) piora em diversos indicadores ao longo da pandemia.

Como notado, um crime cotidianamente silenciado pela sociedade passa a ser ainda mais calado por conta da pandemia. A pesquisa realça que, apenas entre os meses de março a maio de 2020, os casos de violência doméstica cresceram cerca de $6 \%$ em relação aos meses de janeiro e fevereiro, ocasião em que ainda não havia isolamento social no Brasil.

Dentro da mesma lógica, logo após a flexibilização do isolamento social, a partir do mês de junho de 2020, houve uma queda de $27 \%$ das notificações de casos de violência doméstica, o que contribui para evidenciar o impacto da pandemia no aumento da violência contra a mulher. A mesma comparação foi feita com base no número de deferimento de medidas protetivas, que reduziram $84 \%$ nos meses de maior restrição e aumentaram significativamente após a flexibilização $(+229 \%)$.

A pesquisa sugere medidas que possam contribuir para findar o silêncio que envolve os casos de violência doméstica contra a mulher, quais sejam: a) investir em pesquisas de

\footnotetext{
${ }^{15}$ A título de exemplo, em números gerais, a pesquisa "O Raio-X do feminicídio", realizada pelo Ministério Público de São Paulo (BRASIL, 2017), avalia que esse crime se caracteriza por ser de potencial evitável, pois apenas $3 \%$ das vítimas obtiveram medidas de proteção, ao passo que $4 \%$ das vítimas fatais registraram Boletim de Ocorrência. É dizer, por se tratar de um crime ainda muito silenciado, uma vez ganhando voz, poderia ser reduzido consideravelmente.
} 
vitimização; b) fortalecer as linhas de atendimento e denúncia; c) criar a possibilidade de se fazer o Boletim de Ocorrência on-line; e d) aumentar a conscientização e as campanhas de enfrentamento a esse tipo de violência.

Muitas dessas sugestões foram alvo de projetos de lei apresentados em resposta aos altos índices de violência doméstica em tempos de pandemia. A análise das proposituras legislativas, postas em um ordenamento jurídico comum à Lei Maria da Penha, permitirá saber a que nível as estratégias de enfrentamento à violência contra a mulher permaneceram coerentemente orientadas no período de pandemia.

\section{AS PROPOSITURAS LEGISLATIVAS DA CÂMARA DOS DEPUTADOS EM RESPOSTA À VIOLÊNCIA DOMÉSTICA PRATICADA DURANTE O ISOLAMENTO SOCIAL}

A presente pesquisa buscou, a partir de uma perspectiva criminológica crítica e tendo como premissa os princípios delineados pela Lei Maria da Penha, analisar os projetos de lei apresentados na Câmara dos Deputados enquanto reação ao problema da violência doméstica agravado pela crise sanitária da Covid-19.

O objeto de estudo foram todas as proposições ${ }^{16}$ que carregaram o tema "violência doméstica" acompanhado dos termos "Covid-19", "coronavírus" ou "pandemia", ao passo que a análise sobre elas teve como foco responder a dois questionamentos: a) quais foram as características das proposituras legislativas apresentadas; e b) como as proposituras impactam no problema que buscam solucionar.

Como o que se pretendeu foi analisar as reações legislativas relacionadas à crise sanitária e, especialmente, as justificativas apresentadas pelas parlamentares para tanto, em um primeiro momento pouco nos importou o conteúdo de leis resultantes de votação ("output") ou a tramitação que tiveram dentro da Casa Legislativa, embora teçamos comentários nesse sentido ao final.

\footnotetext{
${ }^{16}$ Foram catalogados o total de 23 projetos de lei, quais sejam: PL 322/2021; PL 108/2021; PL 83/2021; PL 4252/2020; PL 4133/2020; PL 3505/2020; PL 3423/2020; PL 3223/2020; PL 2960/2020; PL 2920/2020; PL 2762/2020; PL 2688/2020; PL 2434/2020; PL 2190/2020; PL 2013/2020; PL 1930/2020; PL 1552/2020; PL 1458/2020; PL 1444/2020; PL 1368/2020; PL 1319/2020; PL 1291/2020; PL 1267/2020. O período pesquisado compreendeu do dia 26/02/2020, data em que foi confirmado o primeiro caso de Covid-19 em território brasileiro, ao dia 26/02/2021, de modo a englobar toda a atividade legislativa no período de um ano de pandemia. Foram mantidos fora da pesquisa o PL 52/2021, o PL 3289/2020 e o PL 5601/2020, por não guardarem pertinência direta com o tema.
} 
Nesse sentido, o primeiro ponto que salta aos olhos entre as proposituras desta pesquisa é que a grande maioria delas buscou ferramentas alheias ao direito penal quando se debruçaram sobre a questão da violência doméstica. Dos 23 projetos de lei analisados, 20 deles tiveram como objetivo o fornecimento de algum tipo de defesa ou assistência à mulher em situação de violência doméstica; 02 deles tiveram como finalidade desabilitar o agressor; e, por último, 01 buscou o aumento de penas segundo uma lógica de prevenção geral negativa.

A fim de facilitar a remição às proposituras segundo seus objetivos nos parágrafos seguintes, optamos por classificá-las em categorias - "A" e "B" -, como exposto na tabela 01.

Tabela 01 Quantidade de projetos de lei segundo seus objetivos

\begin{tabular}{lll}
\hline objetivo & quantidade & categoria \\
\hline fornecer defesa ou assistência & 20 & $\mathrm{~A}$ \\
\hline desabilitar o agressor $*^{*}$ & 02 & $\mathrm{~B}$ \\
\hline aumentar penas & 01 & $\mathrm{~B}$ \\
\hline
\end{tabular}

* O PL 3423/2020 pode ser classificado nas categorias "fornecer defesa ou assistência" e "desabilitar o agressor”, porém optamos por inclui-lo nessa segunda por ser sua característica predominante.

Esse dado indica uma inclinação consciente em depositar o foco legislativo na questão da vitimização quando o assunto é violência contra a mulher ${ }^{17}$, como demonstrado ser esse o fator mais adequado para a cessação ou evitação das agressões ${ }^{18}$.

Em análise pormenorizada, considerando ainda que cada propositura pode dispor de uma redação que abarque mais de um tema ${ }^{19}$, é possível verificar que em nosso universo de análise houve 10 projetos de lei que visaram a ampliar uma rede de amparo à mulher em

\footnotetext{
17 A análise aqui posta representa um nicho específico de tratamento penal quando comparada com levantamentos feitos por Frade (2007) e Campos (2010), tendo em vista que as proposituras legislativas tendem, de maneira geral, a instituir formas de recrudescimento punitivo em busca da solução de problemas.

${ }^{18}$ Shecaira e Ifanger (2019) indicam que a aplicação de meios repressivos para o enfrentamento da violência contra a mulher tem sido preferida quando da aplicação da Lei Maria da Penha, embora não seja opção adequada para resolver o problema posto. Assim também indica Andrade (2003).

${ }^{19}$ Como alguns projetos de lei possuem mais de uma proposta de alteração legislativa, podem estar incluídos em mais de uma das finalidades mencionadas. $\mathrm{O}$ universo da pesquisa assim se constitui:

a) ampliar rede de amparo: PL 322/2021, PL 4252/2020, PL 4133/2020, PL 3505/2020, PL 3423/2020, PL 3223/2020, PL 2960/2020, PL 2762/2020, PL 1552/2020, PL 1458/2020;

b) proporcionar denúncia de violência: PL 108/2021, PL 83/2021, PL 2920/2020, PL 2688/2020, PL 2190/2020

PL 1930/2020, PL 1458/2020, PL 1368/2020, PL 1291/2020;

c) estender medidas de afastamento: PL 2013/2020, PL 1444/2020, PL 1368/2020, PL 1291/2020;

d) criar rede de informação: PL 1458/2020, PL 1368/2020, PL 1291/2020, PL 1267/2020;

e) alterar cumprimento de pena: PL 3423/2020;

d) confiscar instrumentos de violência: PL 2434/2020;

f) incluir causa de aumento de pena: PL 1319/2020.
} 
situação de violência doméstica; 09 projetos que pretenderam proporcionar o alcance a uma denúncia de violência; 04 projetos cuja finalidade envolvia estender o prazo das medidas de afastamento; outros 04 que buscaram criar uma rede de informação; e, por fim, agora representando uma pequena fração de proposições repressivas, 01 projeto que pretendeu alterar o cumprimento de penas, 01 projeto que visou a confiscar instrumentos de violência (arma de fogo) e 01 projeto cuja finalidade foi criar uma causa de aumento de pena.

Tabela 02 Número de vezes em que um tema apareceu entre as proposições

\begin{tabular}{lll}
\hline tema & $\mathbf{n .}^{\mathbf{0}}$ de vezes & categoria \\
\hline ampliar rede de amparo & 10 & $\mathrm{~A}$ \\
\hline proporcionar denúncia de violência & 09 & $\mathrm{~A}$ \\
\hline estender medidas de afastamento & 04 & $\mathrm{~A}$ \\
\hline criar rede de informação & 04 & $\mathrm{~A}$ \\
\hline alterar cumprimento de pena & 01 & $\mathrm{~B}$ \\
\hline confiscar instrumentos de violência & 01 & $\mathrm{~B}$ \\
\hline incluir causa de aumento de pena & 01 & $\mathrm{~B}$ \\
\hline
\end{tabular}

É interessante notar que as justificativas empregadas nos projetos de lei listados na categoria "B" também demonstram uma inclinação a salvaguardar a mulher em situação de violência doméstica, muito embora a alteração proposta por eles não se debruce efetivamente sobre a questão da vitimização. Por esse motivo entendemos que suas alterações são inócuas, tendo em vista que somente passam a impressão de estarem tratando o problema ${ }^{20}$.

Foi possível observar que a maioria dos projetos de lei apresentados partiu de parlamentares cuja sigla se posiciona, no espectro político-partidário, à esquerda ou, no limite, ao centro ${ }^{21}$. O Partido dos Trabalhadores (PT) esteve presente em 09 das proposições analisadas; o Partido Comunista do Brasil (PCdoB), o Partido Socialismo e Liberdade (PSOL)

\footnotetext{
${ }^{20}$ O PL 1319/2020 sugere aplicar em dobro as penas decorrentes da prática de violência doméstica em período pandêmico, apesar de diversos estudos demonstrarem que o aumento da punição não possui relação com a diminuição da prática de crimes. A esse respeito, ver Rusche e Kirchheimer (2004) e Foucault (2013). O PL 2434/2020 impõe a remoção da arma de fogo do autor da violência doméstica como forma de amenizar o impacto do convívio familiar, medida que já se encontra prevista na Lei Maria da Penha e que, ao final, pouco importa se o convívio do agressor com a mulher em situação de violência ainda persiste. Por último, o PL 3423/2020 busca, dentre tantas outras propostas, vedar a progressão de regime de sujeitos condenados por violência doméstica enquanto perdurarem os efeitos da crise sanitária, como forma de evitar o seu reingresso em sociedade, ao passo que ignora os diversos impactos também presentes no sistema carcerário, o ideal de reintegração social e os malefícios pessoais inerentes à permanência no cárcere, sobretudo durante período pandêmico. Nesse sentido, ver Goffman (2015).

${ }^{21}$ Baseado em análise feita por Maciel et al. (2018).
} 
e o Partido da Social Democracia Brasileira (PSDB) estiveram envolvidos em outros 07 projetos de lei cada.

Tabela 03 Quantidade de proposituras em que cada partido político esteve envolvido

\begin{tabular}{ll}
\hline partido político & PLs envolvidos \\
\hline Partido dos Trabalhadores - PT & 09 \\
\hline Partido Comunista do Brasil - PCdoB & 07 \\
\hline Partido Socialismo e Liberdade - PSOL & 07 \\
\hline Partido da Social Democracia Brasileira - PSDB & 07 \\
\hline Partido Socialista Brasileiro - PSB & 06 \\
\hline Democratas - DEM & 05 \\
\hline Partido Social Liberal - PSL & 05 \\
\hline Outros (13) & 2,5 (média) \\
\hline
\end{tabular}

No que diz respeito à representatividade da pauta, em sucinto recorte é possível afirmar que as 20 pessoas mais engajadas com as alterações legislativas são mulheres. Ainda, 11 proposituras possuem autoria exclusiva de mulheres; 08 possuem autoria exclusiva de homens; e, em um universo comum, apenas 04 contam com autoria mista. Em números absolutos, ao todo 44 deputadas aparecem como autoras ou coautoras de projetos de lei, em contraste com 24 deputados ${ }^{22}$.

Tabela 04 Representação de congressistas nas proposituras legislativas por sexo biológico

\begin{tabular}{llll}
\hline sexo biológico & representação & proposituras & média \\
\hline mulheres & 44 & 15 & 0,34 \\
\hline homens & 24 & 12 & 0,50 \\
\hline
\end{tabular}

Outro ponto que merece destaque é o momento em que os projetos de lei foram apresentados. Quase a totalidade deles foi proposta nos primeiros meses em que a pandemia da Covid-19 adquiriu crescimento exponencial no Brasil, sobretudo como forma de resposta

\footnotetext{
22 É oportuno mencionar que os números aqui indicados significam mais uma persistência e presença nas proposituras legislativas do que uma análise qualitativa. A título de exemplo, citamos o PL 108/2021 e o PL 83/2021, que são de autoria de um mesmo deputado e idênticos entre si, bem como semelhantes ao PL 2920/2020. O mesmo ocorre entre o PL 1368/2020 e o PL 1291/2020. Esse dado fica evidente quando consideramos a média de proposituras indicada na tabela 04 .
} 
emergencial e tendo como base as experiências internacionais de que já se tinha notícia ${ }^{23}$ seja em termos de crise sanitária, para a qual destacamos casos como os de países europeus que já vinham registrando fatalidades, ou em termos de violência contra a mulher.

Tabela 05 Quantidade de projetos de lei apresentados a cada mês

\begin{tabular}{ll}
\hline mês/ano & quantidade \\
\hline fevereiro/20 & --- \\
\hline março/20 & 03 \\
\hline abril/20 & 07 \\
\hline maio/20 & 05 \\
\hline junho/20 & 03 \\
\hline julho/20 & --- \\
\hline agosto/20 & 02 \\
\hline setembro/20 & --- \\
\hline outubro/20 & --- \\
\hline novembro/20 & --- \\
\hline dezembro/20 & --- \\
\hline janeiro/21 & --- \\
\hline fevereiro/21 & 03 \\
\hline
\end{tabular}

É de se notar que a apresentação de novas proposituras legislativas teve alta conforme o avanço da pandemia no Brasil e, posteriormente, sofreu forte queda em julho, logo após a aprovação do PL n. ${ }^{0}$ 1291/2020 em ambas as casas do Congresso Nacional. É possível que esse evento tenha significado a satisfação das demandas que eram levantadas.

O momento em que novas proposituras deixaram de ser registradas, em setembro, coincide com o período em que o país experimentou uma reabertura social, tendo em vista que os índices de contaminação e fatalidades passaram a sofrer queda em território nacional. $\mathrm{Na}$ mesma lógica, verificamos leve surgimento de novas proposituras em fevereiro de 2021, momento em que uma segunda onda de contaminações e novas demandas por isolamento social ganham corpo no Brasil.

Existe ainda uma correlação entre as proposições legislativas e a comunicação dos riscos na sociedade em crise. Tendo em vista que as notificações do crescimento de casos de violência doméstica surgiram a partir do noticiário e relatórios oficiais, é inegável a relevância

\footnotetext{
${ }^{23}$ Esse fenômeno comporta explicação na linha da teoria da sociedade de risco, proposta por Beck (2011), inclinada à compreensão de que, em decorrência da rapidez com que ocorrem as mudanças em uma sociedade moderna, segue também uma preocupação com o futuro próximo e uma tendência à antecipação a catástrofes. Entendemos que as incertezas potencializadas com o surgimento do novo vírus e sua propagação a nível pandêmico, bem como o prognóstico do futuro alertado pelas experiências internacionais no que tange à violência contra a mulher em período de isolamento social, foram motores determinantes para uma onda de pânico imediato que recaiu sobre os países atingidos tardiamente.
} 
que esses meios possuíram enquanto formadores de uma agenda ("agenda setting") das proposituras legislativas ${ }^{24}$. Em nosso universo de representação, dos 23 projetos de lei analisados, 18 deles fizeram menção a algum dado externo em suas justificativas.

Tabela 06 Projetos de lei segundo menção a dado externo

\begin{tabular}{ll}
\hline dado externo & quantidade \\
\hline matéria jornalística & 03 \\
\hline estudo com dados oficiais & 09 \\
\hline matéria jornalística e estudo com dados oficiais & 06 \\
\hline não mencionam dado externo & 05 \\
\hline
\end{tabular}

Por último, é relevante considerar que a grande maioria das proposituras analisadas visaram a efetuar alterações com vigência de caráter temporário, ao passo que somente 03 buscaram instituir legislação de efeito permanente ${ }^{25}$. Essas últimas, diferente do que pode aparentar, não pretenderam ser oportunistas no sentido de passar alterações desproporcionais de modo emergencial ${ }^{26}$, mas sim incluir mudanças que tornassem o leque legislativo apto a reagir de forma mais eficiente à conjuntura do momento e a situações semelhantes futuras.

Tabela 07 Projetos de lei segundo o período de vigência

\begin{tabular}{ll}
\hline período de vigência & quantidade \\
\hline temporária & 20 \\
\hline permanente & 03 \\
\hline
\end{tabular}

\footnotetext{
${ }^{24} \mathrm{O}$ "agenda setting" é aqui compreendido dentro da lógica da teoria da comunicação. No escopo de Barros Filho (1995), o fenômeno insere no debate político representações capazes de influenciar nas matérias e decisões políticas. O efeito observado na pesquisa foi o de que relatórios oficiais e notícias sobre o aumento de casos de violência doméstica guardaram relação causal com as justificativas apresentadas, de modo que enunciaram a relevância e necessidade de uma resposta ao problema no dado momento histórico. Nesse sentido, é de se reconhecer que o "agenda setting" dos meios de comunicação e publicação de relatórios oficiais guardou íntima relação com a definição de agenda política.

${ }^{25}$ Referimo-nos ao PL 4133/2020, ao PL 2920/2020 e ao PL 2190/2020. No que diz respeito aos projetos de lei classificados na categoria "B" da tabela 01 deste trabalho, todos foram apresentados como proposituras de caráter temporário.

${ }^{26}$ Como exposto por Bechara (2008), situações tidas como emergenciais usualmente significam um risco à manutenção de direitos e garantias individuais, pois notadamente invocadas para justificar um recrudescimento da legislação penal com o objetivo de solucionar problemas imediatos. A consequência natural é a eventual superação do risco, ao passo que as alterações legislativas e seus efeitos permanecem no ordenamento jurídico de modo definitivo. Esse movimento, porém, não foi observado na pesquisa.
} 
Ao final, é pertinente notar que, em um universo de 23 projetos de lei apresentados na Câmara dos Deputados, somente 01 deles foi aprovado em ambas as Casas Legislativas e transformado em lei; e outros 02 deles seguiram para o Senado Federal, ainda não tendo sido apreciados até a conclusão dessa pesquisa ${ }^{27}$.

O PL n. ${ }^{\circ}$ 1291/2020, aprovado e transformado em lei, teve importância ao: a) incluir na categoria de serviços essenciais aqueles de amparo à mulher em situação de violência doméstica e determinar a continuidade de seus atendimentos, em especial presencialmente; b) fixar a realização prioritária de exame de corpo de delito no local em que ela se encontrar; c) levar à criação de canais de comunicação eletrônica de situações de violência contra a mulher e não excludentes do atendimento presencial; d) possibilitar a concessão de medidas protetivas por meio eletrônico; e) prorrogar todas as medidas protetivas em atividade pelo tempo que durar o estado de emergência sanitária; f) fixar o repasse com urgência das ligações obtidas pela Central de Atendimento à Mulher - Ligue 180; e g) levar à promoção de campanhas informativas sobre a prevenção da violência doméstica.

Tabela 08 Situação dos projetos de lei analisados até a conclusão da pesquisa

\begin{tabular}{ll}
\hline situação & quantidade \\
\hline transformados em lei & 01 \\
\hline aguardando apreciação do senado & 02 \\
\hline tramitando na câmara & 12 \\
\hline arquivados & 08 \\
\hline
\end{tabular}

Há que se reconhecer uma resposta em regra ponderada da Câmara dos Deputados ao dar continuidade às proposituras mais pertinentes e urgentes ao trato do problema da violência doméstica agravada pela crise sanitária da Covid-19. Dentre os projetos de lei classificados na categoria "B" da tabela 01 , um deles se encontra arquivado, outro teve declarada sua prejudicialidade e o último deles ainda aguarda despacho inicial pelo presidente da Casa Legislativa.

\section{CONCLUSÃO}

27 O PL 1291/2020, apresentado em 30 de março de 2020, contou com autoria conjunta de diversas parlamentares, tendo adquirido regime de tramitação de urgência e sido, por fim, transformado na Lei Ordinária n. ${ }^{\circ}$ 14.022/2020 em 07 de julho de 2020. O PL 1444/2020 e o PL 1552/2020, apresentados no mês de abril de 2020, foram aprovados na Câmara no mês de julho e seguiram para apreciação pelo Senado Federal. 
Em que pese o reconhecimento internacional das desigualdades entre homens e mulheres, as dinâmicas inerentes à sociedade patriarcal continuam a criar expectativas e gerar pressupostos sobre a mulher, capazes de dar vazão a relações de dominação e violência no âmbito doméstico, de maneira simbólica ou material, física ou psicológica.

A ampla comunicação do problema percebido em maior escala teve como consequência natural o surgimento de respostas a fim de diminuir seus impactos. Com a análise dos projetos de lei apresentados na Câmara dos Deputados, foi possível perceber em que nível estiveram alinhados àquelas disposições originalmente estabelecidas pela Lei Maria da Penha.

Antes de buscar a resposta através de um maior expansionismo penal, foi observado que a Câmara dos Deputados se debruçou, em larga medida, sobre as questões aptas a garantir maior independência e autonomia da mulher em situação de violência doméstica, bem como o acesso dela ao poder público e a meios de comunicação das situações de opressão.

A inclinação das proposituras legislativas nessa direção, sobretudo em circunstância caracterizada pelo risco social, apta a reclamar respostas populistas, foi analisada como positiva. Por esse motivo, entendemos que as propostas apresentadas na Câmara dos Deputados estiveram alinhadas às diretrizes da Lei Maria da Penha, enquanto política de Estado estrategicamente orientada à retomada da autonomia da mulher sobre si mesma. 


\section{REFERÊNCIAS}

ANDRADE, Vera Regina Pereira de. Sistema penal máximo x cidadania mínima: Códigos da violência na era da globalização. Porto Alegre: Livraria do Advogado Editora, 2003.

BARATTA, Alessandro. Criminologia crítica e crítica do direito penal. 6. ed. Tradução de Juarez Cirino dos Santos. Rio de Janeiro: Revan, 2011.

BARROS FILHO, Clóvis de. Ética na comunicação: da informação ao receptor. São Paulo: Moderna, 1995.

BEAUVOIR, Simone de. O segundo sexo. Rio de Janeiro: Nova Fronteira, 2009.

BECHARA, Ana Elisa. Discursos de emergência e política criminal: o futuro do direito penal brasileiro. Revista da Faculdade de Direito da USP, v. 2009, p. 60-90, 2008.

BECK, Ulrich. Sociedade de risco: rumo a uma outra modernidade. 2. ed. Tradução de Sebastião Nascimento. São Paulo: Editora 34, 2011.

BOURDIEU, Pierre. A dominação masculina. 11. ed. Rio de Janeiro: Bertrand Brasil, 2012.

BRASIL. Decreto $n^{0}$ 1973, de 01 de agosto de 1996. Promulga a Convenção Interamericana para Prevenir, Punir e Erradicar a Violência contra a Mulher, concluída em Belém do Pará, em 9 de junho de 1994. Brasília, Disponível em:

http://www.planalto.gov.br/ccivil_03/decreto/1996/D1973.htm. Acesso em: 27 mar. 2021.

BRASIL. Decreto $n^{\circ}$ 4377, de 13 de setembro de 2002. Promulga a Convenção sobre a Eliminação de Todas as Formas de Discriminação contra a Mulher, de 1979, e revoga o Decreto no 89.460, de 20 de março de 1984. Brasília, Disponível em:

http://www.planalto.gov.br/ccivil_03/decreto/2002/d4377.htm. Acesso em: 27 mar. 2021.

BUTLER, Judith. Problemas de gênero: feminismo e subversão da identidade. Rio de Janeiro: Civilização Brasileira, 2018.

CAMPOS, Carmen Hein de; CARVALHO, Salo de. Tensões atuais entre a criminologia feminista e a criminologia crítica: a experiencia brasileira. In: CAMPOS, Carmen Hein de. (Org.). Lei Maria da Penha Comentada em uma Perspectiva Jurídico-Feminista. Rio de Janeiro: Lumen Juris, v., p. 143-169, 2011.

CAMPOS, Marcelo da Silveira. Crime e Congresso Nacional: uma análise da política criminal aprovada de 1989 a 2006. São Paulo: IBCCRIM, 2010.

FOUCAULT, Michel. Vigiar e punir. 41. ed. Petrópolis: Vozes, 2013.

FRADE, Laura. O que o Congresso Nacional brasileiro pensa sobre a criminalidade. Tese (Doutorado em Sociologia). Brasília: Departamento de Sociologia, Universidade de Brasília, 2007. 
GIANNINI, Renata Avelar et al. Violência Contra Mulheres: como a pandemia calou um fenômeno já silencioso. Instituto Igarapé: a think and do tank, Rio de Janeiro, AE 51, p. 0140, dez. 2020. Disponível em: https://igarape.org.br/wp-content/uploads/2020/12/2020-12-08AE-51_Violencia-contra-mulheres.pdf. Acesso em: 29 mar. 2021.

GOFFMAN, Erving. Manicômios, prisões e conventos. 9. ed. Tradução de Dante Moreira Leite. São Paulo: Perspectiva, 2015.

MACIEL, Ana Paula Brito et al. Partidos políticos e espectro ideológico: parlamentares, especialistas, esquerda e direita no Brasil. Revista Eletrônica de Ciência Política, v. 8, p. 72-88, 2018.

MASSARO, João Paulo Gomes. A Justiça Restaurativa Como Alternativa Ao Direito Penal Retributivo Sob O Prisma Da Vitimologia Nos Casos De Violência Doméstica E Familiar Contra A Mulher. 2021. 158 f. Dissertação (Mestrado) - Curso de Direito, Pontifícia Universidade Católica de Campinas, Campinas, 2021.

MENDES, Soraia da Rosa. Criminologia Feminista: novos paradigmas. São Paulo: Saraiva, 2014.

MINISTÉRIO PÚBLICO DO ESTADO DE SÃO PAULO, Núcleo de Gênero. Raio X do feminicídio em São Paulo: é possível evitar a morte. São Paulo, 2017. Realização: Núcleo de Gênero. Disponível em:

http://www.mpsp.mp.br/portal/page/portal/Nucleo_de_Genero/Feminicidio/RaioXFeminicidi oC.PDF. Acesso em: 29 mar. 2021.

NETTO, Leônidas de Albuquerque et al. Violência contra a mulher e suas consequências. Acta Paulista de Enfermagem, 2014.

ONU Mulheres. Violência contra as mulheres e meninas é pandemia invisível, afirma diretora executiva da ONU Mulheres. 2020. Disponível em: https://www.onumulheres.org.br/noticias/violencia-contra-as-mulheres-e-meninas-epandemia-invisivel-afirma-diretora-executiva-da-onu-mulheres/. Acesso em: 29 mar. 2021.

OPAS/OMS Brasil. Folha informativa - Violência contra as mulheres. 2017. Disponível em: https://www.paho.org/bra/index.php?option=com_content\&view=article\&id=5669:folhainformativa-violencia-contra-as-mulheres\&Itemid=820. Acesso em: 29 mar. 2021.

PEREZ-VINCENT, Santiago et al. COVID-19 Lockdowns and Domestic Violence: evidence from Two Studies in Argentina. Inter American Development Bank, 2020.

PIMENTEL, Amanda; MARTINS, Juliana. O Impacto da Pandemia na Violência de Gênero no Brasil. In: FÓRUM BRASILEIRO DE SEGURANÇA PÚBLICA. Anuário Brasileiro de Segurança Pública 2020. Edição XIV. São Paulo, 2020. Disponível em: https://forumseguranca.org.br/wp-content/uploads/2021/02/anuario-2020-final-100221.pdf. Acesso em: 29 mar. 2021. 
RADBRUCH, Gustav. Filosofia do Direito. São Paulo: Martins Fontes, 2004.

RUSCHE, Georg; KIRCHHEIMER, Otto. Punição e estrutura social. 2. ed. Tradução de Gizlene Neder. Rio de Janeiro: Revan, 2004.

SAFFIOTI, Heleieth. Gênero, patriarcado, violência. 1. ed. São Paulo: Fundação Perseu Abramo, 2004.

SHECAIRA, Sérgio Salomão; IFANGER, Fernanda Carolina de Araujo. Uma crítica ao uso do sistema penal no enfrentamento da violência contra a mulher. Revista Brasileira De Ciências Criminais, v. 161, p. 309-329, 2019.

UNITED NATIONS. Department of Economic and Social Affairs. The World's Women 2015: Trends and Statistics. New York, 2015. Disponível em:

https://unstats.un.org/unsd/gender/downloads/worldswomen2015_report.pdf. Acesso em: 29 mar. 2021.

WILLEMAN, Marianna Montebello. A proteção internacional aos direitos da mulher. Revista EMERJ, v. 3, p. 155-170, 2000. 